\title{
$\operatorname{arCOS} D E S I G N$
}

\section{Momentos de inovação na história da Todeschini}

Daniele D. Ellwanger (ESDI/UERJ, Brasil)

daniele_ellwanger@hotmail.com

UERJ - Escola Superior de Desenho Industrial

Rua Evaristo da Veiga 95, Lapa, Rio de Janeiro, RJ. CEP: 20031-040

Lígia Medeiros (ESDI/UERJ, Brasil)

ligia@esdi.uerj.br

Lucy Niemeyer (ESDI/UERJ, Brasil)

niemeyer@openlink.com.br 


\title{
Momentos de Inovação na História da Todeschini
}

Resumo: O presente artigo teve como objetivo identificar os principais momentos de inovação que se suscederam no decorrer da história da Todeschini. Desde sua inauguração, em 1939, tal empresa investiu fortemente na aquisição de novas tecnologias e no desenvolvimento de novos produtos, bem como no aprimoramento destes, entre outras aplicações, para que se mantivesse presente no mercado de móveis retilíneos (em módulos) produzidos em série, a partir das últimas três décadas até os dias de hoje. Tais tomadas de decisões foram assertivas, à medida que contribuíram para acirrar a competitividade entre as empresas e para estimular, consequentemente, o crescimento da própria Todeschini. Esses acontecimentos trouxeram à tona questões relacionadas ao design diante dos contextos industrial e comercial.

Palavras-chave: Inovação, design, trajetória da Todeschini.

\section{Moments of Innovation in the Todeschini History}

\begin{abstract}
This study aimed to identify the key innovative moments that followed the course of Todeschini's history. Since its opening in 1939, the company has heavily invested in acquiring new technologies and developing new products, as well as working in their improvement, among other applications, in order to remain present in the market of rectilinear furniture (modules) in serial production, from the last three decades up to the present day. These decisions were assertively taken as they contributed to intensify the competition among companies and consequently stimulate Todeschini's own growth. These events have raised issues related to design facing industrial and commercial contexts.
\end{abstract}

Keywords: Innovation, design, Todeschini's history. 


\section{Introdução}

A partir de entrevistas realizadas com funcionários da Todeschini, bem como com o Sr. Nelson Ivan Petzold, durante os anos de 2007 e 2008, objetivou-se identificar os principais momentos de inovação que ocorreram na história desta firma, desde sua produção inicial relativa a acordeões até sua aproximação e, em seguida, sua dedicação exclusiva à área moveleira. Tais momentos foram cruciais para que a empresa tomasse novos rumos e tornasse-se cada vez mais competitiva no mercado.

Para tanto, utilizaram-se o Manual de Oslo e os estudos de Vivien Walsh, entre outras referências, como aportes para o entendimento dos tipos de inovação existentes, os quais foram apontados na trajetória da Todeschini.

\section{Histórico da Empresa e Principais Acontecimentos em Termos de Inovação}

Em entrevista realizada em Bento Gonçalves, no Rio Grande do Sul, em 2007, o entrevistado $A^{1}$ relatou que, desde 1939 , a Todeschini já atuava no mercado, mas envolvida com a produção de acordeões (Figura 1). A empresa teve como fundador Luiz Matheus Todeschini e, com o passar dos anos, a presidência esteve sempre nas mãos de familiares. Além desses, havia ainda a participação de acionistas, principalmente representados por funcionários. No início, a empresa possuía em torno de 40/50 trabalhadores.

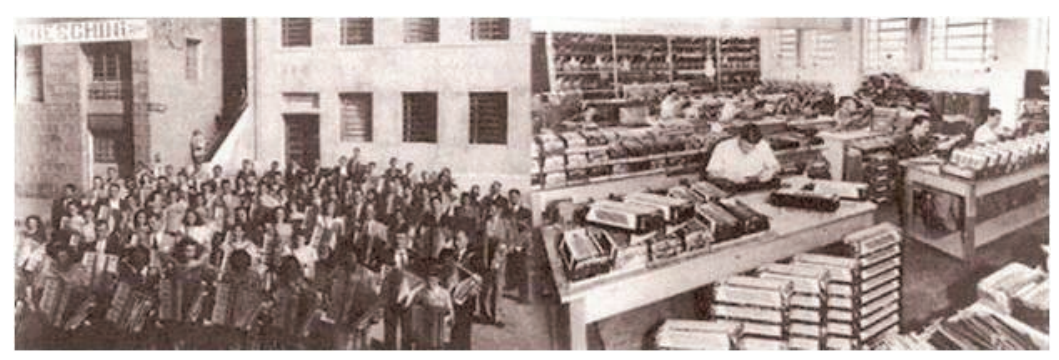

Figura 1. Fábrica de acordeões, 1939 (TODEschini, [2006?]).

Nesse período, a produção de acordeões era pertinente porque tais instrumentos faziam parte de um contexto cultural que se firmou no Rio Grande do Sul, por consequência do processo de imigração italiana que se instaurou neste Estado, iniciado em 1875. Esses instrumentos são representativos da cultura material desse povo, a qual se caracteriza pelas relações que ocorrem entre as pessoas e os objetos.

\footnotetext{
${ }^{1}$ Gerente de negócios há 36 anos na Todeschini, até então.
} 
De acordo com Menezes, citado por Barcelos (2009, p. 34), define-se cultura material por "aquele segmento do meio físico que é socialmente apropriado pelo homem”, de maneira que este intervém, de alguma forma, nos elementos deste meio, segundo propósitos e normas culturais. Tal conceito abrange "artefatos, estruturas, modificações da paisagem, como coisas animadas (uma sebe, um animal doméstico), e, também, o próprio corpo [...] (deformações, mutilações, sinalações) ou, ainda, os seus arranjos espaciais (um desfile militar, uma cerimônia litúrgica)”. Para analisá-lo, deve-se considerá-lo "como suporte material, físico, imediatamente concreto, da produção e reprodução da vida social”. Dessa forma, os artefatos, parte considerável de que trata a cultura material, podem ser ponderados como produtos e como vetores de relações sociais.

De um lado, eles são o resultado de certas formas específicas e historicamente determináveis de organização dos homens em sociedade (e este nível de realidade está em grande parte presente, como informação, na própria materialidade do artefato). De outro lado, eles canalizam e dão condições a que se produzam e efetivem, em certas direções, as relações sociais (idem, p. 34)

Na primeira metade do século XX, as meninas, que faziam quinze anos, queriam de aniversário uma festa ou um acordeão Todeschini, relatou o entrevistado A. Assim, os acordeões são vistos como objetos que "formam seus significados muito menos por suas qualidades materiais e individuais e muito mais pelos contextos, pelas situações sociais nas quais estão inseridas e em quais foram usadas" (HILBERT, 2009, p. 16-17). Tais objetos contam histórias, incorporam histórias das pessoas, como também influenciam as suas vidas (idem, p. 19).

Na segunda metade da década de 1960, com a entrada de instrumentos de corda e, em seguida, de aparelhos elétricos/eletrônicos no mercado, "houve uma queda vertiginosa na venda de acordeão. Por exemplo, vinha uma produção de 1.200 por dia, ela foi para 200", revelou o entrevistado A. Nesse momento, a Todeschini contratou os profissionais José Bornancini e Nelson Petzold para encontrarem alguma solução frente à crise. Como a estrutura do acordeão era composta, além das palhetas de aço, por madeira de lei e compensado, todos materiais importados, e, consequentemente, tanto o maquinário utilizado quanto os funcionários trabalhavam bem com estes materiais, resolveu-se, então, investir na área moveleira. 
Segundo a Organização para Cooperação e Desenvolvimento Econômico - OCDE, esse tipo de investimento, característico de empresas do setor privado, promove inovações tecnológicas de produtos, entre outras que estão presentes na figura 2 e serão abordadas no decorrer deste artigo. Nesse caso, a inovação quanto a produto representa-se pela "implantação/comercialização de um produto com características de desempenho aprimoradas de modo a fornecer objetivamente ao consumidor serviços novos ou aprimorados" (OCDE, 2005, p. 21). Considera-se a OCDE como uma das principais entidades responsáveis pelo desenvolvimento do Manual de Oslo, o qual é a fonte internacional primordial "de diretrizes para coleta e uso de dados sobre atividades inovadoras da indústria" (idem, p. 5). Cabe destacar, portanto, que a inovação tecnológica em questão tratou do desenvolvimento de produtos novos, totalmente diferentes daqueles produzidos pela Todeschini até então: deixou-se de se fabricar acordeões para se investir em mobiliário.

Ainda, de acordo com Walsh (1996, p. 516), as inovações tecológicas novas, também chamadas radicais, ocuparam uma posição de destaque em relação às incrementais, diante do cenário industrial, "porque, se elas são bem sucedidas, podem estimular uma série de desdobramentos, em termos de produtos e inovações de processo, e dão origem a novos setores industriais"2. Isso pode ser observado no decorrer da história da própria Todeschini.

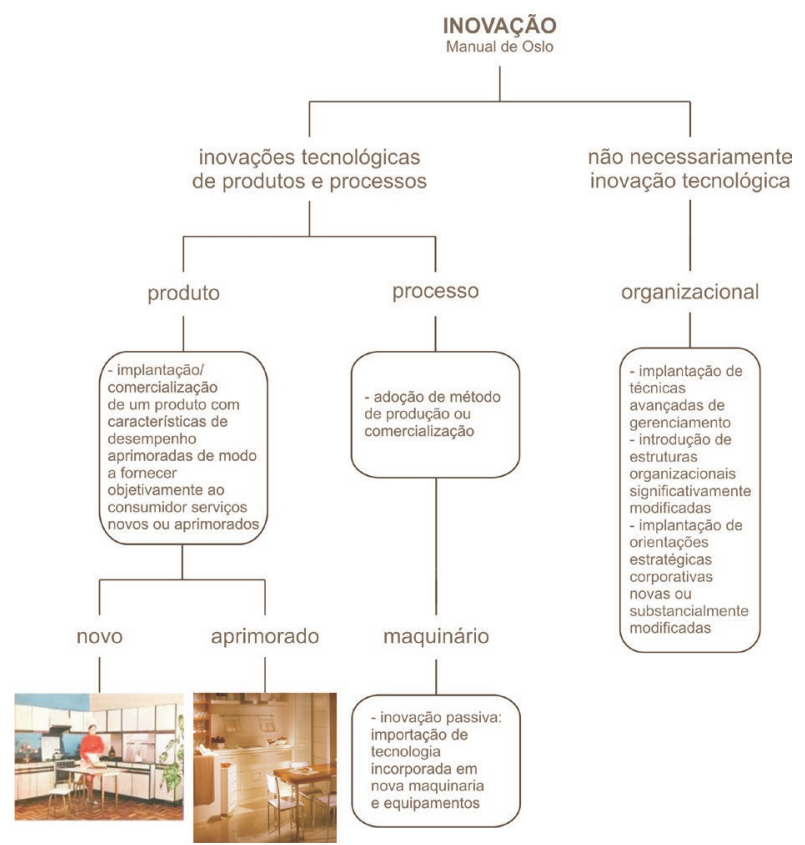

Figura 2. Tipos de inovação decorrentes de investimentos em empresas do setor privado, como é o caso da Todeschini (coleção da autora, 2013).

${ }^{2} \mathrm{O}$ texto em língua estrangeira é: "that is because, if they are particularly successful, they can stimulate a series of related upstream and downstream product and process innovations and give rise to new industrial sectors". 
Na época, as famílias Farina e Fontanari compraram as ações da família Todeschini e passaram a ter o controle acionário da empresa. "Além de móveis de cozinha, se fez móvel de escritório, móveis de sala, móveis de instituto de beleza, caixas camping, luminárias e uma série de produtos, sendo que o que despontou foi o projeto de cozinhas que nós chamávamos, na época, de cozinhas americanas" (Figuras 3 e 4), explicou o entrevistado A.

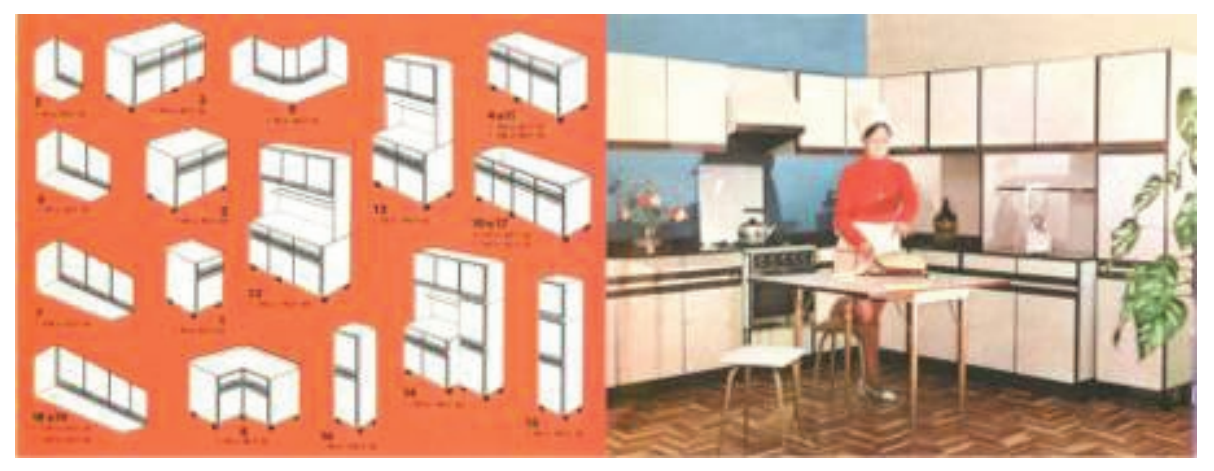

Figura 3. Cozinha modulada da Todeschini, 1968 (coleção de Nelson Petzold).

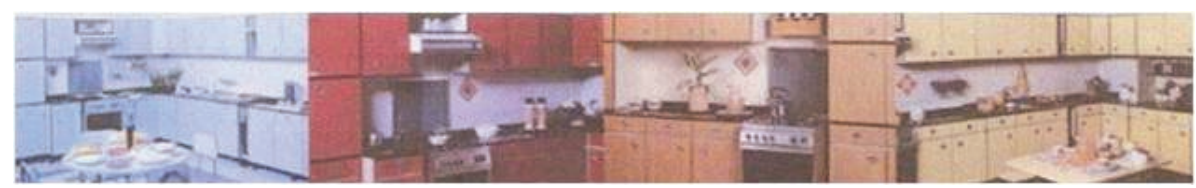

Figura 4. Cozinhas moduladas, década de 1970 (TODESCHINI, [2006?]).

No ano de 1971, logo após o investimento de Farina e de Fontanari, aconteceu um incêndio na indústria, trazendo prejuízos devastadores à mesma. Com o empréstimo dos pavilhões da Feira Nacional do Vinho - FENAVINHO pelo prefeito de Bento Gonçalves, a Todeschini passou a produzir móveis para cozinha, encerrando, definitivamente, a fabricação de acordeões em função da sua complexidade. Quanto ao maquinário, alguma coisa se pôde aproveitar da época dos acordeões, além da existência de uma mecânica que produzia e adequava as máquinas às necessidades da empresa, já que não existia a possibilidade de importação. Esse tipo de adaptação ou fabricação de nova maquinaria considera-se como uma inovação tecnológica, também chamada por inovação passiva (oCDE, 2005).

A partir de 1971, para a produção de móveis, utilizava-se chapa dura de 2,5 mm (conhecida pelas marcas Duratex e Eucatex, por exemplo). Primeiro, as peças eram compostas pela sobreposição de várias chapas até se chegar na espessura de 17/18 mm. Depois, "com a redução de custos, [...] [tinha] uma chapa de um lado, [...] [fazia-se] um recuado com enchimento de madeira e [...] [colocava-se] uma outra por cima. [...] [Fazia-se] a usinagem na máquina 
e [...] [dava-se] o acabamento da peça", descreveu o entrevistado A. O acabamento poderia ser com pintura ou com laminado plástico (conhecido pela marca Fórmica, por exemplo). Além desses materiais, utilizavam-se colas, dobradiças e puxadores.

A empresa era organizada por setores, os quais eram representados pela área industrial, setores comercial e financeiro, com funcionários especializados para cada setor.

A Todeschini sempre buscou abastecer o mercado interno. "Foram poucos os anos em que a exportação superou 4/5\%", revelou o entrevistado A. Na década de 1970, os produtos fabricados pela empresa eram comercializados por redes de lojas, como a Colombo, a Obino e o Ponto Frio, além de outras lojas menores que vendiam especificamente móveis, onde o total chegava a quase 4.000 pontos de venda pelo Brasil.

Em 1993, ocorreu uma transformação muito importante para a empresa, em termos de gerenciamento, mudando sua filosofia de trabalho para gestão administrativa participativa, quando a empresa, então, passou a ouvir e a valorizar mais seus funcionários, por meio de políticas sociais e de benefícios, como o Programa Libra Sisterlina, Programa Compartilhar, Programa Rancho, Programa Vamos Crescer Juntos, além de empréstimos, alimentação, assistência médica e odontológica, atividades sociais e esportivas, benefícios a entidades, o que fez da Todeschini a $8^{\text {a }}$ Melhor Empresa para se Trabalhar no Brasil, em 2006, segundo pesquisa realizada pelo Great Place to Work e publicada pela revista Época; também recebeu o Prêmio de Responsabilidade Social 2006, na categoria Grande Empresa, conforme o Evento promovido pela Assembléia Legislativa do Rio Grande do Sul.

Essa mudança pode ser considerada como inovação organizacional, que compreende, de acordo com a OCDE (2005, p. 131), a implantação de técnicas de gerenciamento e de orientações estratégicas corporativas substancialmente modificadas. Conforme o entrevistado A, o setor administrativo da Todeschini percebeu que deveria investir nos seus funcionários, pois, a partir dos anos de 1980, todas as indústrias passaram a ter acesso às tecnologias e aos financiamentos disponíveis, por exemplo, e as pessoas engajadas no trabalho é que fariam a diferença dentro da organização.

Atualmente, a família Farina possui o controle da presidência e da parte administrativa da Todeschini, além da contribuição de diretores industriais, comerciais e financeiros, entre outros executivos, tendo a empresa um total de 265 acionistas.

A Todeschini, hoje, tem $54.000 \mathrm{~m}^{2}$ de área construída, como mostra a figura 5 , a qual inclui o show room, o setor administrativo, o refeitório e a parte industrial (toda setorizada), e envolve 488 funcionários no total. O maquinário da indústria 
é de última geração, o que a inclui entre as fábricas mais modernas do mundo. $\mathrm{O}$ volume de mercadorias expedidas fica em torno de 330 toneladas por dia. $99 \%$ dessa produção destinam-se ao mercado interno, sendo a exportação quase nula. O principal canal de comercialização da Todeschini é as lojas exclusivas, com um total de 400 espalhadas pelo Brasil. Os materiais utilizados na confecção dos produtos são, basicamente, o aglomerado e o MDF, com acabamentos melamínicos ou pinturas. Os acessórios correspondem a aramados, dobradiças, corrediças e puxadores diferenciados, os quais são fornecidos por empresas subcontratadas.

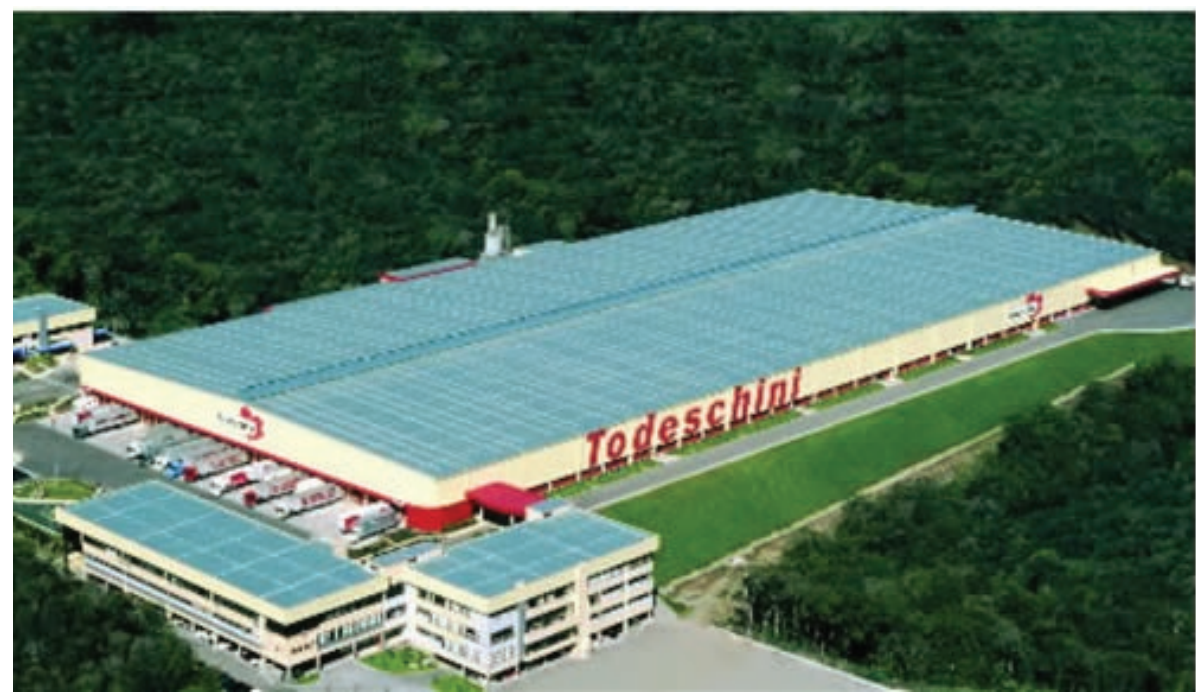

Figura 5. Instalações da Todeschini, em Bento Gonçalves (TODESCHINI, 2008).

A corporação Todeschini também possui outras cinco unidades fabris, as quais correspondem à Todesmade (Cachoeira do Sul-RS), Todesflor (Cachoeira do Sul-RS), Italínea (Bento Gonçalves-RS), Grato (São DesidérioBA) e Todeschini Export (Bento Gonçalves-RS).

A Todeschini produz móveis planejados em módulos componíveis que atendem a todos os ambientes da casa, como sala de estar, sala de jantar, cozinha (Figura 6), escritório (Figura 7), dormitório (Figura 8), dormitório infantil, banheiro, bem como estofado (Figura 9), além de projetos especiais e corporativos para hotéis, bares, cafeterias (Figura 10), restaurantes, clínicas, entre tantos outros ambientes. Na opinião do entrevistado $\mathrm{A}$, os fatores que fazem o sucesso dos produtos da Todeschini referem-se ao design, à qualidade, à diferenciação e ao preço.

No decorrer dos anos, a empresa investiu constantemente no aprimoramento dos móveis produzidos, o que também pode ser considerado como inovação tecnológica, atingida após a difusão de tais produtos (oCDE, 2005, p. 21). Isso se relaciona com a afirmação de Georgiou et al., citados por Walsh (1996, p. 515), ao revelar 
que, por meio da construção de competências específicas, em particular com uma base de conhecimento organizada, as empresas são capazes de desenvolver uma família de projetos dentro de um "corredor tecnológico". As empresas de sucesso são aquelas que continuamente modificam e adaptam seus projetos em resposta a novas tecnologias, produtos concorrentes e mudanças que o usuário precisa ${ }^{3}$.

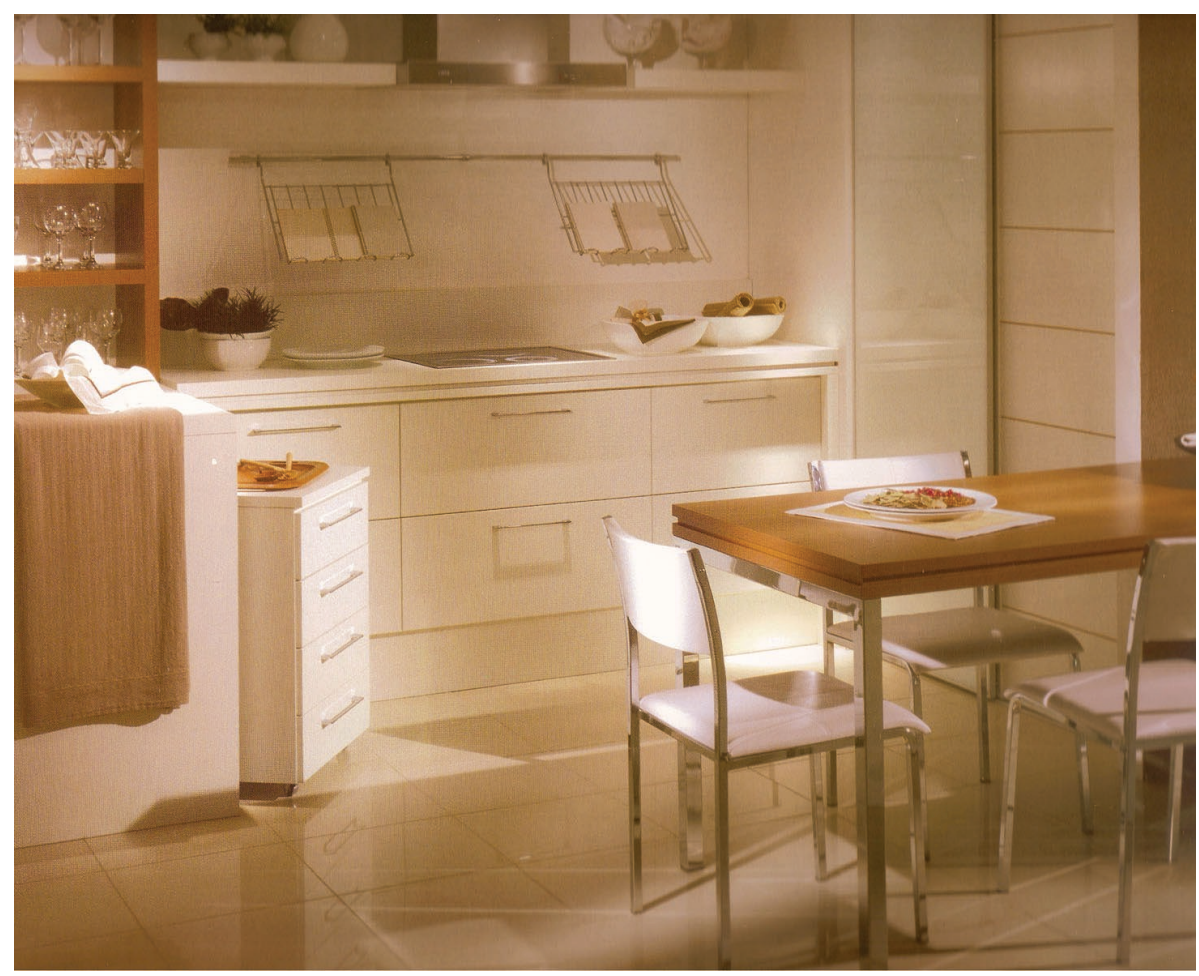

Figura 6. Cozinha Lisa e Gelo da Todeschini (Todeschini, 2006, p. 36).

\footnotetext{
${ }^{3} \mathrm{O}$ texto em língua estrangeira é: "that by building up specific competences, particularly an organised knowledge base, companies are able to develop a family of designs within a 'technological corridor'. The successful companies are those which continuously modify and adapt their designs in response to new technologies, competing products, and changing user needs".
} 


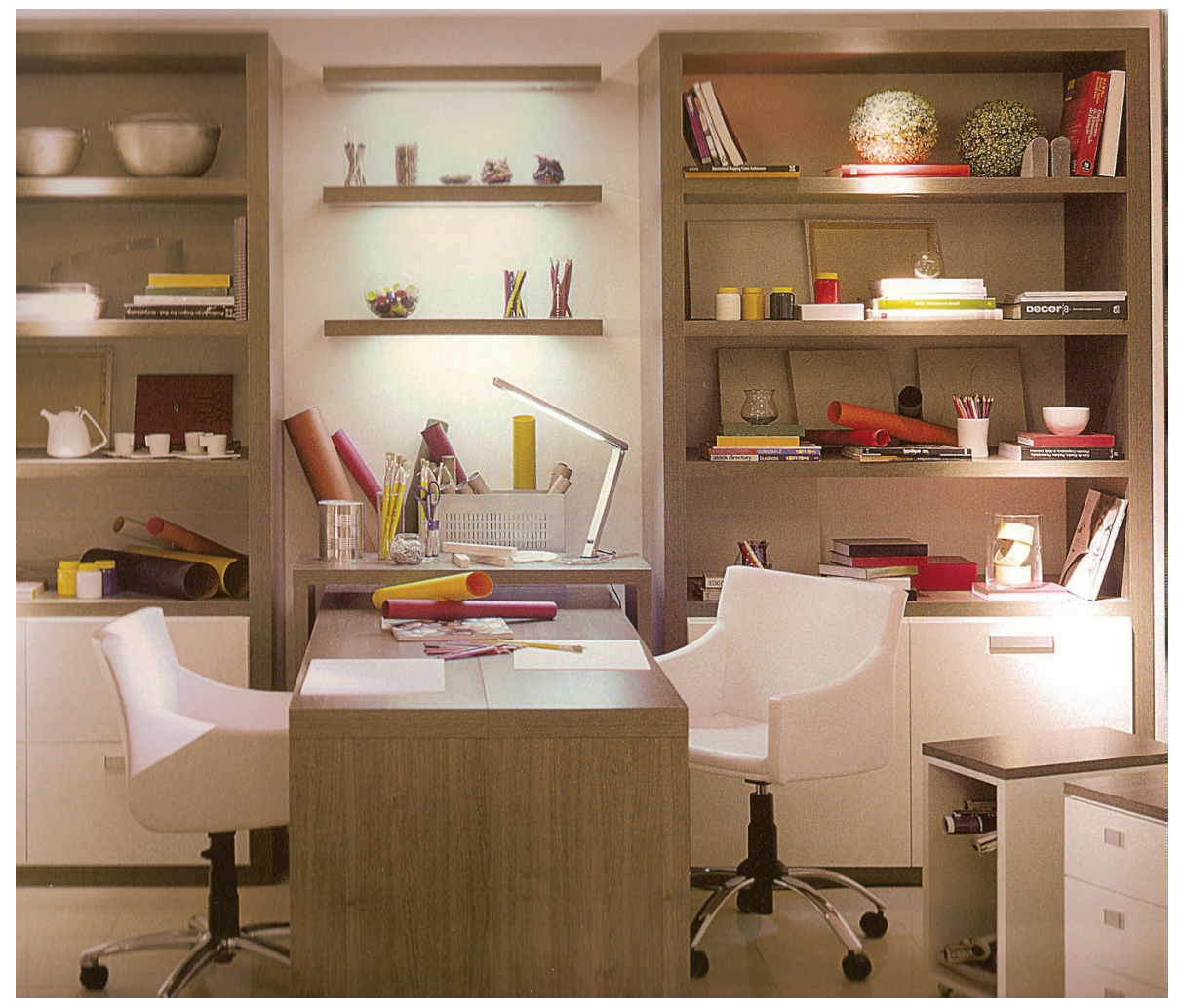

Figura 7. Escritório Lisa da Todeschini (Todeschini, 2006, p. 47).

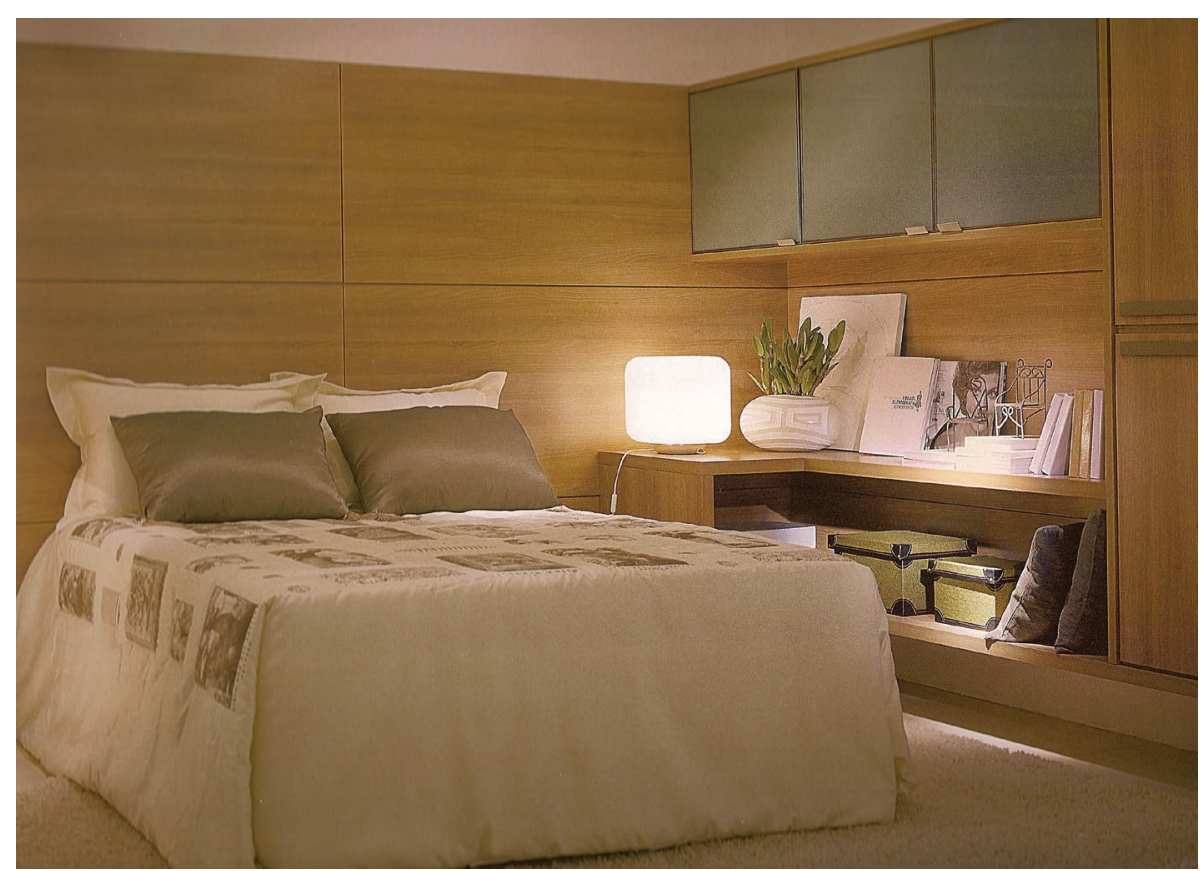

Figura 8. Dormitório Acácia e Jade da Todeschini (TODEsCHINI, 2006, p. 57). 


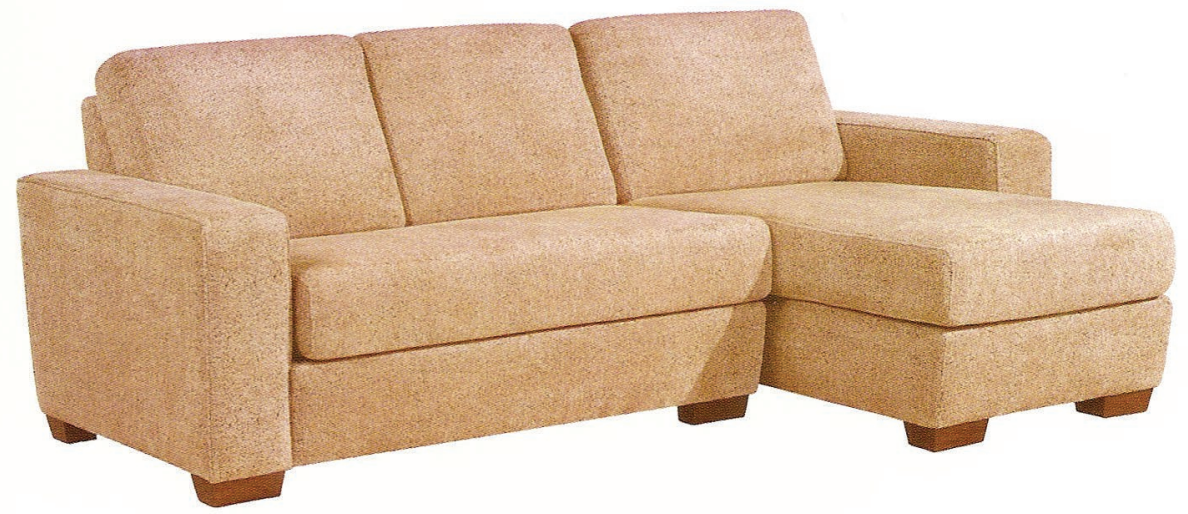

Figura 9. Estofado Ventura da Todeschini (TODEschini, 2006, p. 21).

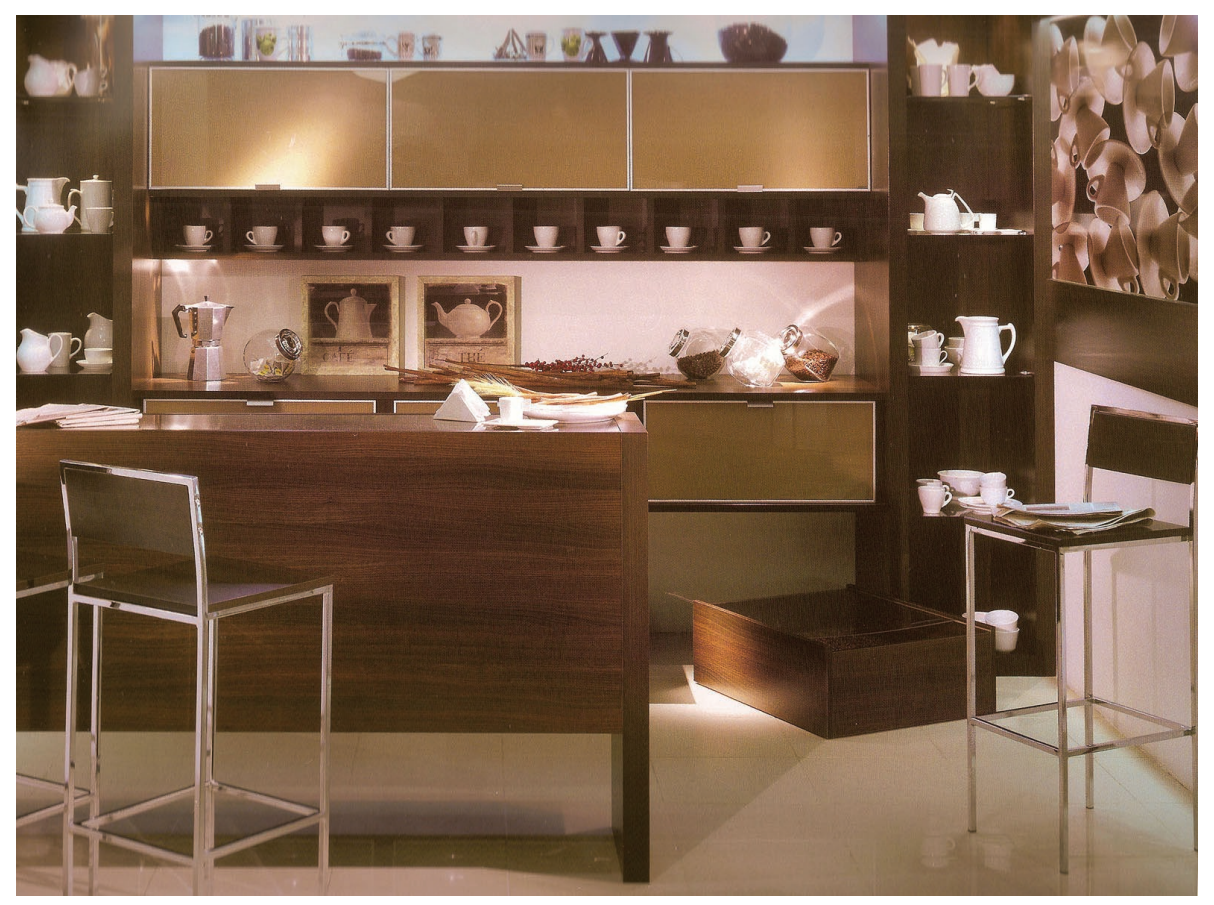

Figura 10. Cafeteria Málagen e Caramelo da Todeschini (ToDEschini, 2006, p. 81).

Em entrevista realizada em Bento Gonçalves, no ano de 2008, quanto ao design na empresa, o entrevistado $\mathrm{B}^{4}$ relatou que o primeiro momento de transformação crucial na Todeschini ocorreu quando os profissionais José Bornancini e Nelson Petzold prestaram consultoria à empresa, sugerindo a passagem da produção de acordeões para móveis, principalmente de cozinhas moduladas com qualidade em design.

\footnotetext{
${ }^{4}$ Arquiteto e assistente técnico na área de projetos para a fábrica, lojas, show room, corporativos e interiores (tarefa esta de tantos outros profissionais e arquitetos no setor de projetos), há dois anos e seis meses com vínculo à empresa, até então, o qual trabalhou anteriormente na secretaria de planejamento urbano de Bento Gonçalves e num escritório de arquitetura.
} 
Nesse momento, percebe-se o design como uma atividade importante a ser desenvolvida na empresa, pois, segundo Walsh (1996, p. 509), as tomadas de decisões resultam em produtos que podem contribuir para o seu sucesso comercial, como aconteceu na Todeschini. As características de tais produtos, como função e aparência, além da questão relativa a custo, são fundamentais de serem trabalhadas para que isso ocorra.

Ademais, conforme Freeman, citado por Walsh (1996, p. 514), “o design é crucial para a inovação na medida em que é no domínio da criatividade onde as ideias são concebidas, mas também onde ocorre o 'acoplamento' entre as possibilidades técnicas e as exigências do mercado ou oportunidades" 5 .

A criatividade, por sua vez, é "definida como a produção de novidade relevante e eficaz" (CROPLEY, 1999, p. 512, grifo do autor). Isso ocorre a partir da avaliação dos fatos, da compreensão do problema, utilizando-se de conhecimentos, habilidades especiais e técnicas, para que sejam alcançadas possíveis soluções, no caso de problemas complexos. Nas indústrias, por exemplo, a ênfase refere-se mais à inovação do que à criatividade, pois, segundo Cropley (1999, p. 519), a primeira "exige não apenas a criação de novidade, mas também [deve-se] colocá-la em prática concreta”7.

A criatividade pode ser considerada "como pré-requisito para a inova-

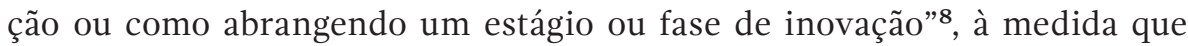
contribui com a introdução "de ideias, produtos, produção e processos de comercialização"9 numa organização empresarial (idem, p. 519). No caso da Todeschini, houve a necessidade de mudança nos rumos da pesquisa que a empresa desenvolvia. No final da década de 1960, conforme Petzold (2008), ele e seu sócio Bornancini corrigiram tais problemas pelo que intuíam, mas tendo "uma bagagem de 40 anos" para embasar esta intuição.

Em pesquisa com várias empresas na Europa, Walsh (1996, p. 511512) observou que algumas delas possuíam departamento direcionado ao desenvolvimento de design, outras tinham setor de P \& D (Pesquisa \& Desenvolvimento), escritório de desenho (como parte do departamento de produção) ou design como responsabilidade do setor de marketing ou de

\footnotetext{
${ }^{5} \mathrm{O}$ texto em língua estrangeira é: "design is crucial to innovation in that it is the domain of creativity where ideas are devised but also where the "coupling' occurs between technical possibilities and market demands or opportunities”.

${ }^{6} \mathrm{O}$ texto em língua estrangeira é: "defined as the production of relevant and effective novelty".

${ }^{7} \mathrm{O}$ texto em língua estrangeira é: "requires not only creating novelty, but also putting it into concrete practice".

${ }^{8} \mathrm{O}$ texto em língua estrangeira é: "as a prerequisite for innovation or as encompassing a stage or phase of innovation".

${ }^{9} \mathrm{O}$ texto em língua estrangeira é: "of ideas, products, production, or marketing processes".
} 
finanças. Aquelas empresas que não possuíam setor relacionado ao design contratavam consultores para desenvolverem esta atividade. Geralmente, essa atitude acontecia porque a empresa não possuía pessoal com habilidade suficiente e adequada para exercer tal função, ou por uma questão de princípio ou estratégia empresarial. Em certos casos, as empresas não tinham setor de design porque carecia de recurso ou não o considerava importante o suficiente para tal investimento.

A falta de um setor específico de design na Todeschini não a impediu de introduzir produtos novos ou aprimorados no mercado, além da inclusão de inovações tecnológicas de processo (maquinário) ou não necessariamente tecnológicas (organizacional) na própria empresa. Isso está em acordo com Walsh (1996, p. 520), quando se compara a Todeschini com as firmas presentes no estudo de tal autora. Walsh (1996, p. 521) ainda informa que, em muitos momentos, quem desenvolveu/desenvolve design eram/são pessoas que não possuíam/possuem formação na área, entre elas engenheiros e arquitetos, como aconteceu na Todeschini.

Atualmente, quanto à Todeschini, o desenvolvimento de design ocorre em escritórios de arquitetura que prestam serviços terceirizados, tendo como exemplo o Vazquez Arquitetos, entre outros, o que revela que a empresa não possui setor próprio de design. O setor de projetos é liderado por uma arquiteta, também com MBA em Marketing, pessoa esta que possui contato com os escritórios e que busca novas informações e novos modelos para os prestadores de serviço em feiras no exterior, como na Itália e na Alemanha, sendo esta ação a principal origem do desenvolvimento de design. Ligado a esta diretora e aos escritórios de arquitetura está a engenharia.

A solicitação de um novo móvel ou a alteração de um produto já existente surge, principalmente, do setor de projetos, pois este recebe pedidos de lojistas, arquitetos e profissionais da área, onde tais informações são repassadas para o escritório de arquitetura responsável pelo processo de desenvolvimento dos projetos. O novo móvel ou a alteração de um produto existente recebe aprovação dos diretores da empresa. Os trabalhos desenvolvidos pelo setor de projetos são realizados em programas como o Auto Cad e o Promob. Segundo Walsh (1996, p. 511), a principal razão pela qual as empresas contratam consultores para o desenvolvimento de um determinado projeto refere-se à falta de habilidade específica dentre seus funcionários. Esse emprego pode ocorrer devido a "uma questão de princípio ou estratégia da empresa, a fim de manter um fluxo de novas ideias"10, por exemplo.

${ }^{10} \mathrm{O}$ texto em língua estrangeira é: "the main reason for employing a consultant was either a general lack of in-house skill, or lack of a particular skill. Some firms employed consultants as a matter of principle or company strategy, in order to maintain a flow of fresh ideas". 
A Todeschini acompanha o nível de aceitação dos seus produtos junto aos usuários finais por intermédio de ligações e e-mails recebidos, por informações extraídas da relação entre lojistas, arquitetos ou designers, com os clientes, além de aplicação de questionários realizada diretamente com os usuários.

Finalizando a entrevista, o entrevistado B disse que o design se dá pela relação entre "o melhor meio de produção, marketing e qualidade", esta referente "às formas elegantes, aos materiais e à funcionalidade". Com isso, ele acredita que o produto pode ser visto como completo. Essa corresponde a uma das definições identificadas no estudo de Walsh (1996, p. 510), o qual apresentou que as empresas possuem entendimentos variados sobre o que é design. Algumas consideram essa atividade ligada, exclusivamente, à adequação ao uso ou desempenho; ou à aparência ou à moda. Outras empresas acrescentam a importância de se desenvolver algo que venda ou gere lucros; facilidade de utilização; eficiência na produção e uso de materiais; segurança e durabilidade.

\section{Considerações finais}

A trajetória da Todeschini apresenta importantes momentos que foram cruciais tanto para o seu desenvolvimento, em termos de porte, quanto para que se mantivesse presente no mercado competitivo. Inicialmente, com a produção de acordeões, desde 1939, a empresa procurou atender ao contexto cultural que se firmou no Rio Grande do Sul, por consequência do estabelecimento de imigrantes italianos neste Estado. Com a queda na venda de tais produtos, a partir da segunda metade da década de 1960, por conta da entrada de instrumentos de corda e aparelhos elétricos/eletrônicos no mercado, a contratação dos profissionais Bornancini e Petzold foi fundamental para que se encontrasse uma solução frente à crise. Isso levou a empresa a investir na área moveleira, o que promoveu inovações tecnológicas de produtos novos (principalmente móveis para cozinha, além daqueles para escritório, sala, salão de beleza, caixas camping, luminárias, entre outros produtos) e, com o decorrer do tempo, aprimoramentos nos existentes. Após o incêncio, a Todeschini passou a produzir somente móveis para cozinha. As máquinas que restaram após a contingência foram adequadas às novas necessidades da empresa, bem como outras foram criadas para o mesmo fim (inovação tecnológica de maquinário).

Além desses momentos de inovação, houve uma transformação em termos de gerenciamento, em que a Todeschini passou a valorizar seus funcionários, pois percebeu que eles é que faziam a diferença na organização diante do mercado competitivo e frente às tecnologias e insumos que estão acessíveis a todas as empresas. 
Atualmente, a Todeschini possui um pavilhão todo setorizado, com maquinário e utilização de materiais e acessórios de última geração, o que a tornou uma das fábricas mais modernas do mundo. O investimento constante no aprimoramento dos móveis produzidos, representados hoje por móveis planejados em módulos componíveis, faz com que a Todeschini seja considerada uma empresa de sucesso. Inclusive, as tomadas de decisões, no decorrer da história de tal firma, resultaram em produtos que contribuíram para o êxito comercial. A falta de um setor específico de design na Todeschini não a impediu de introduzir produtos novos ou aprimorados no mercado, além da promoção de outras inovações, nem mesmo a ausência de designers.

Mas quais seriam os aspectos fundamentais ou diferenciais para que a empresa mantenha-se competitiva diante do mercado de móveis retilíneos produzidos em série? Neste âmbito, há uma certa estagnação no que se diz respeito à exploração de novas formas. As empresas concorrentes apresentam móveis com resultados formais muito parecidos; não há diferenciação. Talvez, o que traduza o sucesso da Todeschini seja a tradição e a qualidade no desenvolvimento de seus produtos; a eficiência na logística, considerando, principalmente, o investimento no relacionamento com o cliente, seja referente ao menor prazo para entrega dos produtos quanto pela montagem rápida ou atendimento eficaz relativo a algum reparo, por exemplo; ou, ainda, a busca constante pelo aprimoramento de seus produtos e maquinário.

Acredita-se que o sucesso também dependa do investimento em design, por meio da relação entre criatividade, possibilidades técnicas e exigências do mercado ou oportunidades. A inovação coloca em prática as ideias geradas, e a criatividade é vista aqui como pré-requisito para que isto ocorra. Investir numa área como a do design pode criar uma condição dinâmica na própria situação de concorrência, o que contribuiria para o crescimento e o êxito da empresa.

\section{Referências}

BARCELOS, Artur Henrique Franco. De Cultura Material, Memória, Perdas e Ganhos. Métis: história \& cultura, Caxias do Sul, v. 8, n. 16, p. 27-42, jul./dez. 2009.

CROPLEY, Arthur J. Definitions of Creativity. In: RUNCO, Mark; PRITZKER, Steven (Ed.). Encyclopaedia of Creativity. San Diego: Academic Press, 1999.

HILBERT, Klaus. Diálogos entre Substâncias, Cultura Material e Palavras. Métis: história \& cultura, Caxias do Sul, v. 8, n. 16, p. 11-25, jul./dez. 2009. 
OCDE. Organização para Cooperação e Desenvolvimento Econômico. Manual de Oslo: proposta de diretrizes para coleta e interpretação de dados sobre inovação tecnológica. 1992, 1997 e 2005.

PETZOLD, Nelson Ivan. Entrevista degravada, com duração de duas horas. Porto Alegre: 18 de julho de 2008.

TODESCHINI. Coleção Natural Life Todeschini. Catálogo de Produtos. 2006.

TODESCHINI. Histórico. [2006?]. Disponível em: <http://www.todeschini-rs.com.br/Todeschini/Corporate.Corporate.aspx>. Acesso em: 20 maio 2007.

TODESCHINI. Quem Somos. 2008. Disponível em: <http://www.todeschinisa.com.br/Todeschini/Corporate/Corporate.aspx?key=d4ee5a3d-c0b4-4fda-ace5-30ee55d967e7>. Acesso em: 05 maio 2008.

WALSH, Vivien. Design, Innovation and the Boundaries of the Firm. In: Research Policy. No 25, 1996, p. 509-529. 


\section{Como citar}

ELLWANGER, Daniele D.; MEDEIROS, Ligia M. S.; NIEMEYER, Lucy C. R. Momentos de Inovação na História da Todeschini. Arcos Design. Rio de Janeiro: PPD ESDI - UERJ. Volume 9 Número 1 Junho 2016. pp. 104-120. Disponível em: [http:// www.e-publicacoes.uerj.br/index.php/arcosdesign]

\section{DOI}

\section{(c) (i) (5)}

A Revista Arcos Design está licenciada sob uma licença Creative Commons Atribuição - Não Comercial - Compartilha Igual 3.0 Não Adaptada. 